Pacific Journal of Mathematics

FEASIBLE FLOWS AND POSSIBLE CONNECTIONS 


\title{
FEASIBLE FLOWS AND POSSIBLE CONNECTIONS
}

\author{
A. M. Duguid
}

1. Introduction. A number of results in the theory of graphs, including Menger's Theorem [2] and Whitney's Theorem ([1], Chapter 20, [3]), have been shown to follow from the max flow-min cut theorem, which was discovered in the course of study of the flow of goods in a transportation network [4]. Gale [6] has used the max flow-min cut theorem to prove a generalization of a well known combinatorial lemma of Philip Hall [7], and has used his "feasibility theorem" to obtain interesting combinatorial results ${ }^{1}$. The object of this note is to give a slightly more general form of Gale's theorem, and to use this to prove a theorem about directed graphs, which is of interest in connection with communication networks.

Let the network $\left[N, c, c^{*}\right]$ be a set $N$ of nodes with a non-negative capacity $c(x, y)$ restricting flow along the directed edge $x y$, for any $x, y \in N$, and a positive capacity $c^{*}(x)$ restricting the total flows into, or out of, any node $x \in N$. Let $S$ and $S^{\prime}$ be complementary subsets of $N$. The upper bound on flow from $S$ to $S^{\prime}$ imposed by the capacities $c$ and $c^{*}$ will be denoted by $k\left(S, S^{\prime}\right)$ (and is more precisely defined below). Following Gale, we define a demand $d$ on the network to be a realvalued function on the nodes, and $|d(x)|$ is to be thought of as the demand for or the supply of some good at $x$, according as $d(x)$ is positive or negative. The demands $d(x)$ are said to be feasible if there exists a flow in the network, satisfying the capacity restrictions, such that the net flow into (out of) each note is at least (at most) equal to the demand (supply) at that node. Gale's theorem states that a necessary and sufficient condition for the demands $d(x)$ to be feasible is:

For every collection $S$ of nodes, the sum of the demands at the nodes of $S^{\prime}$ must not exceed the capacity $k\left(S, S^{\prime}\right)$.

Gale proves this for the case when there are no capacity restrictions on the nodes, and $k\left(S, S^{\prime}\right)$ is thus the sum of the capacities of edges leading from $S$ into $S^{\prime}$. We show how Gale's argument may be modified to cover the case when there are capacities on the nodes as well as on the edges.

Let $A$ and $B$ be disjoint subsets of the nodes of the directed graph $G$, containing $n$ and $m$ elements respectively. In $\S 3$ we establish a necessary and sufficient condition that from any $r$ nodes of $A$ there are $r$ disjoint paths to any $r$ nodes of $B$, for all $r \leqq \min \{n, m\}$.

Received May 12, 1960. The results reported in this paper were obtained in the course of research sponsored by Bell Telephone Laboratories Inc.

1. These results were also obtained independently, without using flows, by Ryser [8]. 
2. The feasibility theorem. A route from the node $x$ to the node $y$ in the network $\left[N, c, c^{*}\right]$ is a sequence $x_{1}, x_{2}, \cdots, x_{n}$ of nodes of $N$, with $x_{1}=x, x_{n}=y$, and $c\left(x_{i}, x_{i+1}\right)>0, i=1, \cdots, n-1$. The edges $x_{i} x_{i+1}, i=1, \cdots, n-1$, are the stages of the route. If $A$ and $B$ are disjoint subsets of $N$, and route from a node in $A$ to a node in $B$ is called a route from $A$ to $B$. $A$ cut $\sigma$ with respect to $A$ and $B$ is a collection of nodes and edges of positive capacity of the network, such that every route from $A$ to $B$ has either a node or a stage belonging to $\sigma$. For any set $\tau$ of nodes and edges of the network, the capacity $k(\tau)$ of the set $\tau$ is the sum of the capacities of its constituent elements. If $S$ and $S^{\prime}$ are complementary subsets of $N$, and $\Omega_{S}$ is the set of all cuts with respect to $S$ and $S^{\prime}$, then the capacity $k\left(S, S^{\prime}\right)$ of the partition $\left(S, S^{\prime}\right)$ is defined

$$
k\left(S, S^{\prime}\right)=\min _{\Omega_{S}} k(\sigma) .
$$

A flow on the network $\left[N, c, c^{*}\right]$ is defined to be a real valued function $f(x, y), x, y \in N$, such that

$$
\begin{aligned}
& f(x, y)+f(y, x)=0 \\
& f(x, y) \leqq c(x, y) \\
& \sum_{y} f^{+}(x, y) \leqq c^{*}(x) \\
& \sum_{y} f^{+}(y, x) \leqq c^{*}(x),
\end{aligned}
$$

for all $x, y \in N$, where the summations are over all elements of $N$, and $f^{+}(x, y)=f(x, y)$ if $f(x, y)>0$, and is zero otherwise. For any subsets $A$ and $B$ of $N$ and any flow $f$ we define the net flow $f(A, B)$ from $A$ to $B$ by

$$
f(A, B)=\sum_{x \in A y \in B} f(x, y) .
$$

It is intuitively evident that if $S$ and $S^{\prime}$ are complementary subsets of $N$, then the net flow from $S$ to $S^{\prime}$ cannot exceed $k\left(S, S^{\prime}\right)$. To state this formally, omitting the proof, we have:

LEMmA 1. For any partition $\left(S, S^{\prime}\right)$ of the nodes of the network $\left[N, c, c^{*}\right]$, and any flow $f$ on $\left[N, c, c^{*}\right]$, we have:

$$
f\left(S, S^{\prime}\right) \leqq k\left(S, S^{\prime}\right) \text {. }
$$

If $f$ is a flow such that $f(N, x)=0$ unless $x=s$ or $x=s^{\prime}$, we say that $f$ is a flow from $s$ to $s^{\prime}$ whose value is $f(s, N)$. (We denote a one-element set by its unique element.) The max flow-min cut theorem ([2], [4], [5], [6]) may be stated: 
Theorem 1. Let $F$ be the set of flows from $s$ to $s^{\prime}$ and let $Q$ be the set of cuts with respect to $s$ and $s^{\prime}$ of the network $\left[N, c, c^{*}\right]$. Then

$$
\max _{F} f(s, N)=\min _{Q} k(\sigma) .
$$

A demand $d$ on $\left[N, c, c^{*}\right]$ is a real-valued function on $N$. If $A$ is a subset of $N$ we write $d(A)=\sum_{x \in A} d(x)$. A demand $d$ is said to be feasible if there is a flow $f$ such that

$$
f(N, x) \geqq d(x), \quad \text { for all } x \in N \text {. }
$$

Theorem 2. The demand $d$ on the neturork $\left[N, c, c^{*}\right]$ is feasible if, and only if for every subset $S$ of $N$,

$$
d\left(S^{\prime}\right) \leqq k\left(S, S^{\prime}\right)
$$

Proof. The necessity is obvious. For if $d$ is feasible, then there is a flow $f$ such that, for all $S$,

$$
d\left(S^{\prime}\right) \leqq f\left(N, S^{\prime}\right)=f\left(S, S^{\prime}\right)+f\left(S^{\prime}, S^{\prime}\right)=f\left(S, S^{\prime}\right),
$$

and

$$
f\left(S, S^{\prime}\right) \leqq k\left(S, S^{\prime}\right), \quad \text { by Lemma } 1 .
$$

To prove sufficiency we follow Gale [6] in defining a new network $\left[\bar{N}, \bar{c}, \bar{c}^{*}\right]$ by adding two new nodes $s$ and $s^{\prime}$ to $\left[N, c, c^{*}\right]$ and putting

$$
\begin{gathered}
\bar{c}(x, y)=c(x, y), \bar{c}^{*}(x)=c^{*}(x), \text { for all } x, y \in N, \\
\bar{c}^{*}(s)=\bar{c}^{*}\left(s^{\prime}\right)=\infty \\
\bar{c}(s, x)=-d(x), \text { if } d(x)<0 \\
\bar{c}\left(x, s^{\prime}\right)=d(x), \text { if } d(x)>0 \\
\bar{c}(x, y)=0, \text { otherwise } .
\end{gathered}
$$

Let $U^{+}$and $U^{-}$denote the sets of nodes $x$ of $N$ for which $d(x)>0$ and $d(x)<0$, respectively. We shall show that (5) implies that $d\left(U^{+}\right)$ is a lower bound for capacities of cuts of $\left[\bar{N}, \bar{c}, \bar{c}^{*}\right]$ with respect to $s$ and $s^{\prime}$. The edges $x s^{\prime}, x \in U^{+}$, form a cut of capacity $d\left(U^{+}\right)$, which is thus a minimum cut. Hence, by the max flow-min cut theorem, there is a flow $\bar{f}$ from $s$ to $s^{\prime}$ of value $d\left(U^{+}\right)$. Let $f$ be $\bar{f}$ restricted to $\left[N, c, c^{*}\right]$. Then $f$ satisfies (4), as Gale shows, and the demand $d$ is feasible. Thus we need only prove:

Lemma 2. If (5) holds in $\left[N, c, c^{*}\right]$, then $d\left(U^{+}\right)$is a lower bound for capacities of cuts with respect to $s$ and $s^{\prime}$ in $\left[\bar{N}, \bar{c}, \bar{c}^{*}\right]$.

Proof of the lemma. Let $\bar{\sigma}$ be any cut of finite capacity of $\left[\bar{N}, \bar{c}, \bar{c}^{*}\right]$ with respect to $s$ and $s^{\prime}$, and let 


$$
\bar{c}=\sigma \cup \sigma_{s} \cup \sigma_{s}^{\prime},
$$

where $\sigma$ consists of nodes and edges of $\left[N, c, c^{*}\right], \sigma_{s}$ consists of edges of the form $s x$, where $x \in U^{-}$, and $\sigma_{s^{\prime}}$ consists of edges of the form $x s^{\prime}$, where $x \in U^{+}$. Let $\bar{S}_{1}$ consist of $s$ and all nodes $y \in \bar{N}$ such that there is a route $x_{1}, x_{2}, \cdots, x_{n}$, with $x_{1}=s, x_{n}=y, x_{i} \notin \bar{\sigma}, i=1, \cdots, n$, and $x_{i} x_{i+1} \notin \bar{\sigma}, i=1, \cdots, n-1$. It is easy to verify that $s^{\prime} \in \bar{S}_{1}^{\prime}$, the complement of $\bar{S}_{1}$ in $\bar{N}$, and that $\bar{\sigma}$ is a cut with respect to $\bar{S}_{1}$ and $\bar{S}_{1}^{\prime}$. Let

$$
\bar{S}=\bar{S}_{1} \cup\left(\sigma \cap U^{-}\right) .
$$

Then $\bar{\sigma}$ is also a cut with respect to $\bar{S}$ and $\bar{S}^{\prime}$. Now $\bar{S}=S \cup s$ and $\bar{S}^{\prime}=S^{\prime} \cup s^{\prime}$, where $S$ and $S^{\prime}$ are complementary subsets of $N$. It follows that $\sigma$ is a cut of $\left[N, c, c^{*}\right]$ with respect to $S$ and $S^{\prime}$ Hence, if (5) holds,

$$
\bar{k}(\sigma)=k(\sigma) \geqq k\left(S, S^{\prime}\right) \geqq d\left(S^{\prime}\right)=d\left(S^{\prime} \cap U^{+}\right)+d\left(S^{\prime} \cap U^{-}\right) .
$$

Now if $x \in S^{\prime} \cap U^{-}$, then $x \notin \sigma$. But $s \in \bar{S}, x \in \bar{S}^{\prime}$, and $\bar{c}(s, x)$ $=-d(x) 0$. Hence either $s \in \bar{\sigma}$ or $s x \in \bar{\sigma}$. But $k(\bar{\sigma})$ was assumed finite, and $c^{*}(s)=\infty$; so $s x \in \bar{\sigma}$. More precisely, $s x \in \sigma_{s}$. Hence

$$
\bar{k}\left(\sigma_{s}\right) \geqq-d\left(S^{\prime} \cap U^{-}\right) .
$$

If $x \in S \cap U^{+}$, then there is a route $x_{1}, x_{2}, \cdots, x_{n}$ from $s=x_{1}$ to $x=x_{n}$, with no node or stage belonging to $\bar{\sigma}$. But $\bar{c}\left(x, s^{\prime}\right)=d(x)>0$, and $s^{\prime} \notin \bar{\sigma}$. Hence $x s^{\prime} \in \sigma_{s^{\prime}}$, for otherwise $x_{1}, x_{2}, \cdots, x_{n}, s^{\prime}$ would be a route from $s$ to $s^{\prime}$, avoiding the cut $\bar{\sigma}$. Hence

$$
\bar{k}\left(\sigma_{s^{\prime}}\right) \geqq d\left(S \cap U^{+}\right) .
$$

Adding (6), (7) and (8), we get

$$
\bar{k}(\sigma)+\bar{k}\left(\sigma_{s}\right)+\bar{k}\left(\sigma_{s^{\prime}}\right) \geqq d\left(S^{\prime} \cap U^{+}\right)+d\left(S \cap U^{\prime}\right),
$$

that is

$$
k(\bar{\sigma}) \geqq d\left(U^{+}\right) .
$$

This proves the lemma, and hence the theorem.

3. An application. The max flow-min cut theorem and the feasibility theorem hold when the functions $d, c, c^{*}$ and $f$, instead of being real-valued, have values from an arbitrary ordered Abelian group. It is the case of integer-valued flows, capacities, and demands, that is useful in proving combinatorial and graph theoretic results ([2], [6]), and which we shall use in this section.

A path from $a$ to $b$ in a directed graph $G$ is a sequence of nodes 
$a_{1}, a_{2}, \cdots, a_{r}$, with $a_{1}=a$ and $a_{r}=b$, such that there is an arc of $G$ directed from $a_{1}$ to $a_{i+1}, i=1, \cdots, r-1$. The ordered pair of nodes $a_{i} a_{i+1}$ is called the $i$ th step of the path. If $A$ is a subset of the nodes of $G$, then $|A|$ denotes the number of elements in $A$. If $A$ and $B$ are two disjoint subsets of nodes of $G$, then a path from a node in $A$ to a node in $B$ is called a path from $A$ to $B$. In particular, the arc $x y$ is an arc from $A$ to $B$ if $x \in A$ and $y \in B$. Two paths, or two arcs, will be termed disjoint if they have no common node.

Theorem 3. Let $A$ and $B$ be two disjoint sets of nodes of a directed graph $G$. The following properties are equivalent.

I. There is a set of $r$ disjoint paths from any subset of $r$ elements of $A$ to any subset of $r$ elements of $B$, for all $r \leqq \min \{|A|,|B|\}$.

II. For every pair of complementary subsets $S$ and $S^{\prime}$ of the nodes of $G$ there is a set of $r$ disjoint arcs from $S$ to $S^{\prime}$, where $r=\min \left\{|S \cap A|,\left|S^{\prime} \cap B\right|\right\}$.

\section{Proof: \\ $I \rightarrow I I$.}

Let $\left(S, S^{\prime}\right)$ be any partition of the set $N$ of nodes of $G$, let $r=\min \left\{|S \cap A|,\left|S^{\prime} \cap B\right|\right\}$, and let $I_{r}$ and $O_{r}$ be arbitrarily chose subsets of $r$ elements of $S \cap A$ and $S^{\prime} \cap B$ respectively. By $I$, there are $r$ disjoint paths from $I_{r}$ to $O_{r}$. Each of these paths contains at least one arc from $S$ to $S^{\prime}$. Taking one such arc from each path we get a set of $r$ disjoint arcs from $S$ to $S^{\prime}$.

$$
I I \rightarrow I \text {. }
$$

Let $\left[N, c, c^{*}\right]$ be the network on the nodes of $G$ obtained by defining

$$
\begin{aligned}
& c(x, y)= \begin{cases}\infty, & \text { if there is an arc of } G \text { from } x \text { to } y \\
0, & \text { otherwise }\end{cases} \\
& c^{*}(x)=1 \text {, for all } x \in N \text {. }
\end{aligned}
$$

Let $I_{r}$ and $O$, be given subsets of $r$ elements of $A$ and $B$ respectively, and define

$$
d(x)=\left\{\begin{aligned}
1, & \text { for } x \in O_{r} \\
-1, & \text { for } x \in I_{r} \\
0, & \text { for all other nodes of } G .
\end{aligned}\right.
$$

For any partition $\left(S, S^{\prime}\right)$ of $N$,

2 Thanks to a suggestion of the referee, this proof is significantly shorter than my original version. 


$$
\left|S \cap I_{r}\right|+\left|S^{\prime} \cap I_{r}\right|=\left|S \cap O_{r}\right|+\left|S^{\prime} \cap O_{r}\right|
$$

Thus

$$
d\left(S^{\prime}\right)=\left|S^{\prime} \cap O_{r}\right|-\left|S^{\prime} \cap I_{r}\right|=\left|S \cap I_{r}\right|-\left|S \cap O_{r}\right|
$$

Hence

$$
d\left(S^{\prime}\right) \leqq \min \left\{\left|S^{\prime} \cap B\right|,|S \cap A|\right\} .
$$

By II, there is a set of $\min \left\{\left|S^{\prime} \cap B\right|,|S \cap A|\right\}$ disjoint ares from $S$ to $S^{\prime}$. Hence, if $\tau$ is a set of nodes of $G$ such that every arc from $S$ to $S^{\prime}$ is on some node in $\tau$, then $\tau$ has at least $\min \left\{\left|S^{\prime} \cap B\right|,|S \cap A|\right\}$ elements. But with $c$ and $c^{*}$ defined by $(9), k\left(S, S^{\prime}\right)$ is the minimum number of elements in any such set $\tau$. Consequently

$$
k\left(S, S^{\prime}\right) \geqq \min \left\{\left|S^{\prime} \cap B\right|,|S \cap A|\right\} \geqq d\left(S^{\prime}\right) .
$$

Hence, by the feasibility theorem, there is a flow which satisfies the demand $d$ defined by (10). It is easily verified that with $c$ and $c^{*}$ defined by (9), this means that there are $r$ disjoint paths from $I_{r}$ to $O_{r}$.

REMARKs. (a) A similar argument shows that properties $I^{\prime}$ and $I I^{\prime}$ are equivalent, where $I^{\prime}$ is obtained from $I$ by relaxing the condition on the $r$ paths, so that it is only required that no two of them have an arc in common, and $I I^{\prime}$ is obtained from $I I$ by removing the condition that the $r$ arcs be disjoint.

(b) The corresponding theorem for unoriented graphs follows immediatly from Theorem 3 .

\section{REFERENCES}

1. C. Berge, Théorie des graphes et ses applications, Dound, Paris, 1958.

2. G. B. Dantzig and D. R. Fulkerson, In linear inequalities and related systems, Ann. of Math. Studies, No. 38, 215-221.

3. A. M. Duguid, unpublished.

4. L. R. Ford, Jr. and D. R. Fulkerson, Maximal flow through a network, Canad. J. Math., 8 (1956), 397-404.

5. - A simple algorithm finding maximal network flows and an application to the Hitchcock problem, Canad. J. Math., 9 (1957), 210-218.

6. D. Gale, A theorem on flow in networks, Pacific J. Math., 7 (1957), 1073-1082.

7. P. Hall, On representatives of subsets, J. London Math. Soc., 10 (1935), 26-30.

8. H. J. Ryser, Combinatorial properties of matrices of zeros and ones, Canad. J. Math., 9 (1957), 371-377.

BROWN UNIVERSITY

now with Esso Petroleum Company 36 Queen Anne's Gate London, S. W. 1, England 


\title{
PACIFIC JOURNAL OF MATHEMATICS
}

\author{
EDITORS
}

\author{
Ralph S. Phillips \\ Stanford University \\ Stanford, California \\ F. H. Brownell \\ University of Washington \\ Seattle 5, Washington
}

\author{
A. L. Whiteman \\ University of Southern California \\ Los Angeles 7, California \\ L. J. PAige \\ University of California \\ Los Angeles 24, California
}

ASSOCIATE EDITORS
E. F. BECKENBACH
D. DERRY
H. L. ROYDEN
E. G. STRAUS
T. M. CHERRY
M. OHTSUKA
E. SPANIER
F. WOLF

\section{SUPPORTING INSTITUTIONS}

\author{
UNIVERSITY OF BRITISH COLUMBIA \\ CALIFORNIA INSTITUTE OF TECHNOLOGY \\ UNIVERSITY OF CALIFORNIA \\ MONTANA STATE UNIVERSITY \\ UNIVERSITY OF NEVADA \\ NEW MEXICO STATE UNIVERSITY \\ OREGON STATE COLLEGE \\ UNIVERSITY OF OREGON \\ OSAKA UNIVERSITY \\ UNIVERSITY OF SOUTHERN CALIFORNIA
}

\author{
STANFORD UNIVERSITY \\ UNIVERSITY OF TOKYO \\ UNIVERSITY OF UTAH \\ WASHINGTON STATE COLLEGE \\ UNIVERSITY OF WASHINGTON \\ * * * * \\ AMERICAN MATHEMATICAL SOCIETY \\ CALIFORNIA RESEARCH CORPORATION \\ HUGHES AIRCRAFT COMPANY \\ SPACE TECHNOLOGY LABORATORIES \\ NAVAL ORDNANCE TEST STATION
}

Mathematical papers intended for publication in the Pacific Journal of Mathematics should be typewritten (double spaced), and the author should keep a complete copy. Manuscripts may be sent to any one of the four editors. All other communications to the editors should be addressed to the managing editor, L. J. Paige at the University of California, Los Angeles 24, California.

50 reprints per author of each article are furnished free of charge; additional copies may be obtained at cost in multiples of 50 .

The Pacific Journal of Mathematics is published quarterly, in March, June, September, and December. The price per volume (4 numbers) is $\$ 12.00$; single issues, $\$ 3.50$. Back numbers are available. Special price to individual faculty members of supporting institutions and to individual members of the American Mathematical Society: $\$ 4.00$ per volume; single issues, $\$ 1.25$.

Subscriptions, orders for back numbers, and changes of address should be sent to Pacific Journal of Mathematics, 103 Highland Boulevard, Berkeley 8, California.

Printed at Kokusai Bunken Insatsusha (International Academic Printing Co., Ltd.), No. 6, 2-chome, Fujimi-cho, Chiyoda-ku, Tokyo, Japan.

\section{PUBLISHED BY PACIFIC JOURNAL OF MATHEMATICS, A NON-PROFIT CORPORATION}

The Supporting Institutions listed above contribute to the cost of publication of this Journal, but they are not owners or publishers and have no responsibility for its content or policies. 


\section{Pacific Journal of Mathematics}

\section{Vol. 11, No. 2 December, 1961}

Tsuyoshi Andô, Convergent sequences of finitely additive measures........

Richard Arens, The analytic-functional calculus in commutative topological algebras..........................................

Michel L. Balinski, On the graph structure of convex polyhedra in

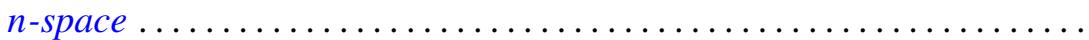

R. H. Bing, Tame Cantor sets in $E^{3}$...

Cecil Edmund Burgess, Collections and sequences of continua in the plane.

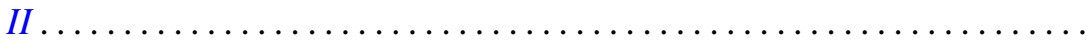

J. H. Case, Another 1-dimensional homogeneous continuum which contains an $\operatorname{arc}$

Lester Eli Dubins, On plane curves with curvature ................. 471

A. M. Duguid, Feasible flows and possible connections .............. 483

Lincoln Kearney Durst, Exceptional real Lucas sequences ................ 489

Gertrude I. Heller, On certain non-linear opeartors and partial differential equations........................................

Calvin Virgil Holmes, Automorphisms of monomial groups

Wu-Chung Hsiang and Wu-Yi Hsiang, Those abelian groups characterized by their completely decomposable subgroups of finite rank ..........

Bert Hubbard, Bounds for eigenvalues of the free and fixed membrane by finite difference methods .........................

D. H. Hyers, Transformations with bounded mth differences. .

Richard Eugene Isaac, Some generalizations of Doeblin's decomposition

John Rolfe Isbell, Uniform neighborhood retracts ..........

Jack Carl Kiefer, On large deviations of the empiric D. F. of vector chance variables and a law of the iterated logarithm...

Marvin Isadore Knopp, Construction of a class of modular functions and forms. II. . .

Gunter Lumer and R. S. Phillips, Dissipative operators in a Banach space....

Nathaniel F. G. Martin, Lebesgue density as a set function ...

Shu-Teh Chen Moy, Generalizations of Shannon-McMillan theorem ...

Lucien W. Neustadt, The moment problem and weak convergence in $L^{2}$

Kenneth Allen Ross, The structure of certain measure algebras...

James F. Smith and P. P. Saworotnow, On some classes of scalar-product algebras.

Dale E. Varberg, On equivalence of Gaussian measures. . 